\title{
The design of optimum composition for skimcoat cement using mixture experiment (case study of PT.X)
}

\author{
J Saragih $^{1^{*}}, \mathbf{Y}$ Reski $^{1}$ \\ ${ }^{1}$ Department of Industrial Engineering,Trisakti University,Jakarta,Indonesia \\ *johnson_saragih@trisakti.ac.id
}

\begin{abstract}
The purpose of this research was to obtain the optimum composition of cement mixture skimcoat., cement skimcoat is a building material used to polish concrete building walls made of 2-3 mm thick, as an indicator of the quality obtained from the company is shown by compressive strength, with a range of $7-10 \mathrm{~N} / \mathrm{mm}^{2}$. to obtain the indicator, the mixture of scimcoat cement consists of three stages, first stage / mixed one with a mixed material : water, latex and pigment, the second stage / mixture of two with the ingredients : white cement, $\mathrm{CaCO}_{3}$ and fine aggregate, for the third stage / mixture of three is composed of a mixture of one, a mixture of two and a polymer. the method used in this research is mixture experiment. where the experimental point is obtained by the formula of randomization $2^{\mathrm{p}}-1$ and three repetitions so that each trial consists of 21 experimental points. The optimum composition obtained for one skimcoat cement sack weigthing $30 \mathrm{~kg}$ is comprised of water of $21.91 \%$, latex $2,6 \%$, pigment $1,78 \%$, white cement $15,12 \%, \mathrm{CaCO}_{3} 2,41 \%$, fine aggregate $27,58 \%$ and polymer $2,5 \%$

Keywords:compressive strength,randomization,mixture experiment
\end{abstract}

\section{Introduction}

Cement is an industrial product consisting of a mixture of raw materials in the form of limestone or limestone and clay or substitute materials with the final result of powder or bulk which will harden when mixed with water. Limestone is a natural material containing calcium oxide compounds $(\mathrm{CaO})$, while clays are natural raw materials containing silica oxide compounds $\left(\mathrm{SiO}_{2}\right)$, aluminum oxide $\left(\mathrm{Al}_{2} \mathrm{O}_{3}\right)$, iron oxide $\left(\mathrm{Fe}_{2} \mathrm{O}_{3}\right)$ and magnesium oxide $(\mathrm{Mg} \mathrm{O})$. To produce it, the raw material is burned to melt with a temperature of $900^{\circ} \mathrm{C}$. Some of mixtures form clinker. Then it is crushed and added with an appropriate amount of cast then packed with the weight of $40 \mathrm{~kg}$ and $50 \mathrm{~kg}$ of each cement sack. According to data obtained from the Association of Cement Indonesia, cement sales every year increased significantly, starting from 2010 until 2015 in average the production reached 64.6 tons per year, See Figure 1. 


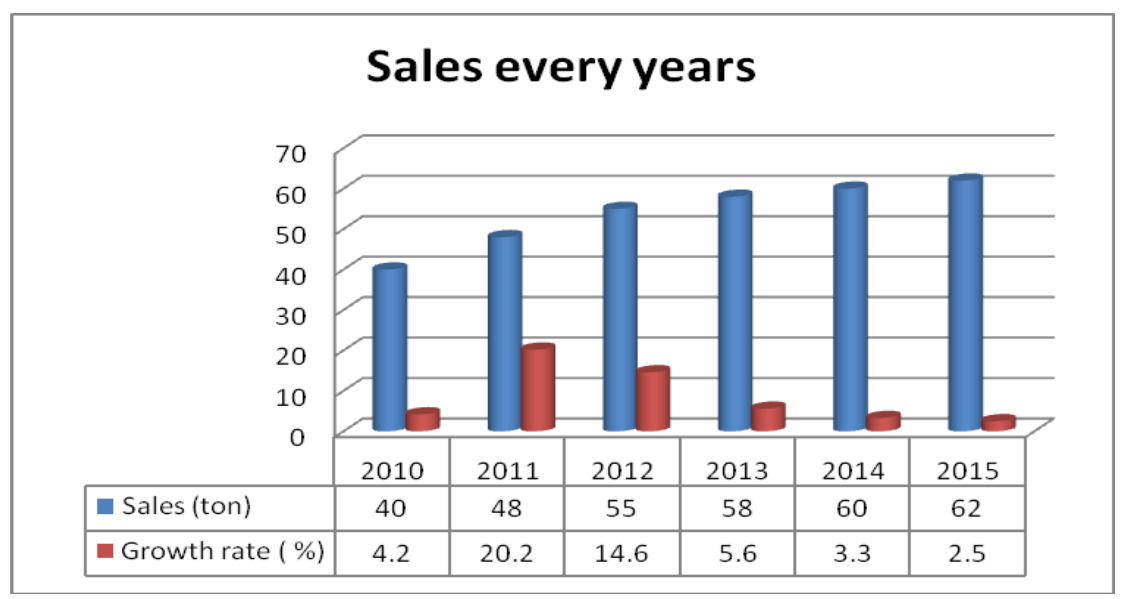

Figure 1. Cement Yearly Sales.

Source : The Association of Cement Indonesia.

The average consumption growth reached $10.08 \%$ per year. With good cement consumption growth, then the increase of cement factory also increases the impact of competition between companies. The competition is getting tighter therefore every company should be able to produce quality cement production. There area companies that use cement as the main raw material of its product.

The resulting product is Plastering that serves as a brick coating wall, AAC Wall, ALC block with thickness of 5-15 mm thick application. One of the mainstay products of this company is Skimcoat which serves as a wall coating with a thickness of 2-3 mm.

One Skimcoat sack is $30 \mathrm{~kg}$ which consists of water content, latex, pigment, white cement, $\mathrm{CaCO}_{3}$, fine aggregate and polymer. The composition of this mixture is thought to affect its viscosity and compressive strength. Compressive strength is an indicator that shows the ability of a material to maintain its integrity under a pressure, or how much pressure the material received before it was crushed or cracked. As is known to measure the quality of a building whether good or not, one of the indicators is Compressive strength $\left(\mathrm{N} / \mathrm{m}^{2}\right)$. While compressive strength $\left(7-10 \mathrm{~N} / \mathrm{m}^{2}\right)$ depends on the composition of the skimcoat mixture. Therefore, it is necessary to determine the optimal mixture composition so that the product specifications can be met by mixture experiment method.

\subsection{Mixture Experiments}

Montomery (1), states that the experiment mixture is a special part of Response Surface Methodology, where factor influencing factors always equal to one. In general mathematical equations, the general model of mathematic can be expresed with :

$$
y=f\left(x_{1}, x_{2}, \ldots \ldots x_{p}\right) \text {,where } x_{1}+x_{2}+x_{8}+x_{4}+\ldots \ldots x_{n}=1
$$

where $y$ is response variable , $\mathrm{x}_{\mathrm{i}}, \mathrm{i}=1,2,3 \ldots \ldots \ldots \ldots . . . \mathrm{p}$ is dependent variable

If $\mathrm{p}=2$, it means for two components, the factor space for the design includes all values of two components that lie on the line segment $x_{1}+x_{2}=1$, with each component being bounded by 0 and 1 . If $\mathrm{p}=3$, its mean for three components, $\mathrm{x}_{1}+\mathrm{x}_{2}+\mathrm{x}_{3}=1$, can be stated at 3-dimension of cubical with $\mathrm{x} 1, \mathrm{x} 2, \mathrm{x} 3$ ranges from 0 to $1(0<\mathrm{x} 1, \mathrm{x} 2, \mathrm{x} 3<1)$.

\subsection{Simplex Designs}

Simplex designs are used to study the effects of mixture components on the response variable. A $\{\mathrm{p}, \mathrm{m}\}$ simplex lattice design for $\mathrm{p}$ components consists of point defined by the following coordinate settings: the proportions assumed by each component take the $m+1$ equally space value fom 0 to 1 , 


$$
x_{i}=0, \frac{1}{m}, \frac{2}{m}, \frac{3}{m} \cdots \cdots 1 \quad i=1,2,3 \cdots \cdots p
$$

And all possible combination (mixture) of the proportions from Equation 1, are used. As an example, let $\mathrm{p}=3$ and $\mathrm{m}=2$. Then

$$
x_{i}=0, \frac{1}{2}, 1 \quad i=1,2,3
$$

And the simplex lattice consist of the following six runs:

$$
\left(x_{1}, x_{2}, x_{3}\right)=(1,0,0),(0,1,0),(0,0,1),\left(\frac{1}{2}, \frac{1}{2}, 0\right),\left(\frac{1}{2}, 0, \frac{1}{2}\right),\left(0, \frac{1}{2}, \frac{1}{2}\right)
$$

In general the number of points in a $\{\mathrm{p}, \mathrm{m}\}$ simplex lattice design is

$$
N=\frac{(p+m-1) !}{m !(p-1) !} \text { so if }\{2,3\} \text {, we get } N=\frac{(2+3-1) !}{2 ! \cdot 3 !}=6
$$

\subsection{Simplex Centroid Design}

An alternative to the simplex lattice design is the simplex centroid design. In p components simplex centroid design, there are $2^{\mathrm{p}}-1$ points, coresponding to the $\mathrm{p}$ permutation of

$$
\begin{aligned}
& (1,0,0, \ldots \ldots \ldots \ldots, 0) \text {, the }\left(\begin{array}{l}
p \\
2
\end{array}\right) \text { permutation of }\left(\frac{1}{2}, \frac{1}{2}, 0, \ldots \ldots, 0\right) \text { the }\left(\begin{array}{c}
p \\
3
\end{array}\right) \text { permutations of } \\
& \qquad\left(\frac{1}{3}, \frac{1}{3}, \frac{1}{3}, 0, \ldots \ldots, 0\right) \text { and the overall centroid }\left(\frac{1}{p}, \frac{1}{p}, \frac{1}{p}, \frac{1}{p}, \ldots \ldots ., \frac{1}{p}\right)
\end{aligned}
$$

A crticism of the simplex design described above is that most of the experimental runs occur on the boundary of the region and, consequently, include only p-1 of the components.It is interior of the region or the region where the blends will consist of all $\mathrm{p}$ mixture experiments.

Mixture models differ from the usual polynomials employed in response surface work because of the constraint $\sum_{i=1}^{p} x_{i}=1$. The standards forms of the mixture models that are in wide spread use :

Linear :

$$
E(y)=\sum_{i=1}^{p} \beta_{i} x_{i}
$$

Quadratic:

with $\mathrm{x} 1+\mathrm{x} 2+\mathrm{x} 3 \ldots \ldots . . \mathrm{xp}=1$

$$
E(y)=\sum_{i=1}^{p} \beta_{i} x_{i}+\sum \sum_{i<j}^{p} \beta_{i j} x_{i} x_{j}+\sum \sum_{i<j}^{p} \delta_{i j} x_{i} x_{j}\left(x_{i}-x_{j}\right)+\sum \sum_{i<j<k} \sum \beta_{i j k} x_{i} x_{j} x
$$

Full cubic:

$$
E(y)=\sum_{i=1}^{p} \beta_{i} x_{i}+\sum \sum_{i<j}^{p} \beta_{i j} x_{i} x_{j}+\sum \sum_{i<j}^{p} \delta_{i j} x_{i} x_{j}\left(x_{i}-x_{j}\right)+\sum \sum_{i<j<k} \sum \beta_{i j k} x_{i} x_{j} x_{k}
$$

Special cubic:

$$
E(y)=\sum_{i=1}^{p} \beta_{i} x_{i}+\sum \sum_{i<j}^{p} \beta_{i j} x_{i} x_{j}+\sum \sum_{i<j<k} \sum \beta_{i j k} x_{i} x_{j} x_{k}
$$




\section{Research Methodology}

The methodology used in this research is mixture experiment method which conducted in laboratory consisting of three experiments and the point of the experiment is done by randomizing with Minitab software version 14 . Step by step of a mixtures are:

1. The first mixture consists of water, latex and pigment mixing done for three minutes in the mixer dissolver machine.

2. The second mixture comprises a mixture of white cement, $\mathrm{CaCO}_{3}$, fine aggregate for five minutes in a hard mixer machine.

3. The third mixture comprises a mixture of step one, a mixture of step two and polymer carried out for two minutes in a Hobart mixer machine.

\section{Result and Discussion}

Discussion conducted in this research is to generate randomization point using Minitab version 14 . The limit of one mixture in the manufacture of scimcoat cement are as follows:

Table 1. Components of the first mixture.

\begin{tabular}{ccc}
\hline Components & Lower bound & Upper bound \\
\hline Water & 0.75 & 0.85 \\
Latex & 0.1 & 0.2 \\
Pigment & 0.05 & 0.15 \\
\hline
\end{tabular}

The experiment point is built with the formula: $2^{\mathrm{p}}-1$, Where $\mathrm{p}=3$ with three replications. Then obtained as many as 21 point experiment where the variable response is viscosity. Obtained results are as follows:

Table 2: Estimated Regression Coeficients for Viscositas.

\begin{tabular}{cccccc}
\hline Term & Coef & SE Coef & T & P & VIF \\
\hline Water & -189 & 155,4 & $*$ & $*$ & 4180 \\
Latex & -3388 & 3810,0 & $*$ & $*$ & 77565 \\
Pigment & 575 & 4057,0 & $*$ & $*$ & 37718 \\
Water*Latex & 5859 & 5631,7 & 1,04 & 0,315 & 101680 \\
Water*Pigment & 1517 & 5631,7 & 0,27 & 0,791 & 43022 \\
Latex*Pigment & -10455 & 5631,7 & $-1,86$ & 0,083 & 1076 \\
\hline
\end{tabular}

According to Table 2, we have the equation of mathematical model as follows:

$$
\hat{y}_{V}=-189 x_{W}-3388 x_{L}+575 x_{P}+5859 x_{W} * x_{L}-1517 x_{W} * x_{P}-10455 x_{L} * x_{P}
$$

Where : $\hat{y}_{V}=$ Viscositas (centipoice), $\mathrm{x}_{\mathrm{w}}=$ Water, $\mathrm{x}_{\mathrm{L}}=$ Latex and $\mathrm{x}_{\mathrm{P}}=$ Pigment

Then two mixed experiments were conducted, still using the 2p-1 formula, with three replications, in which the mixed component was performed as in Table 3:

Table 3. Componens of the two mixture.

\begin{tabular}{ccc}
\hline Components & Lower bound & Upper buond \\
\hline White Cement & 0,20 & 0,30 \\
$\mathrm{CaCO}_{3}$ & 0,40 & 0,50 \\
Fine Aggregate & 0,30 & 0,40 \\
\hline
\end{tabular}

The result of the experiments, we can see of the Table 4 
Table 4. Estimated Regression Coeficients for Intensity.

\begin{tabular}{cccccc}
\hline Term & Coef & SE Coef & T & P & VIF \\
\hline White Cement & 2029 & 2218 & $*$ & $*$ & 84264 \\
CaCO $_{3}$ & 888 & 1188 & $*$ & $*$ & 82087 \\
Fine Aggregate & -990 & 1717 & $*$ & $*$ & 101950 \\
White Cement*CaCO & -6491 & 5388 & $-1,20$ & 0,247 & 91570 \\
White Cement*Fine Aggregate & 1909 & 5388 & 0,35 & 0,728 & 53989 \\
CaCO3*Fine Aggregate & 1309 & 5388 & 0,24 & 0,811 & 186289 \\
\hline
\end{tabular}

According to Table 4, we have the equation of mathematical model as follows:

$$
\hat{y}_{I}=2029 x_{w}+888 x_{C a}-990 x_{F}-6491 x_{W} * x_{F}+1909 x_{W} * x_{F}+1309 x_{C a} * x_{F}
$$

Where : $\hat{y}_{I}=$ Intensity, $\mathrm{x}_{\mathrm{Ca}}=\mathrm{CaCO}_{3}, \mathrm{x}_{\mathrm{W}}=$ White Cement, $\mathrm{x}_{\mathrm{F}}=$ Fine Aggregate

Having obtained the mixture of one and two, then for the mixture of three coupled with polymer and mixed components are shown in Table 5:

Table 5. Componens of mixture of three.

\begin{tabular}{ccc}
\hline Components & Lower bound & Upper bound \\
\hline Mixture of one & 0,25 & 0,29 \\
Mixture of two & 0,70 & 0,74 \\
Polymer & 0,01 & 0,05 \\
\hline
\end{tabular}

The mixture of three, the response variable is Compressive Strength $\left(\mathrm{N} / \mathrm{mm}^{2}\right)$. Similarly, the experimental point obtained in the mixture of three is 21 point and the mathematical model is as follows (see Table 6):

Table 6. Estimated Regression Coeficients for Compressive Strength.

\begin{tabular}{cccccc}
\hline Term & Coef & SE Coef & T & P & VIF \\
\hline Mixture of one & -3602 & 3262,7 & $*$ & $*$ & 6690038 \\
Mixture of two & -520 & 466,4 & $*$ & $*$ & 1000565 \\
Polymer & 1283 & 4685,3 & $*$ & $*$ & 145810 \\
Mixture of one*Mixture of two & 6923 & 6214,1 & 1,11 & 0,283 & 12327550 \\
Mixture of one *Polymer & -4077 & 6214,1 & $-0,66$ & 0,522 & 16792 \\
Mixture of two*Polymer & 1373 & 6214,1 & 0,22 & 0,828 & 127765 \\
\hline
\end{tabular}

According to Table 6, we have equation of mathematic model as follows:

$\hat{y}_{C}=-3602 x_{\text {Mone }}-520 x_{\text {Mtwo }}+1283 x_{P}+6923 x_{\text {Mone }} * x_{\text {Mtwo }}-4077 x_{\text {Mone }} * x_{P}+1373 x_{\text {Mtwo }} * x_{P}$. (9)

Where : $\hat{y}_{c}=$ Compressive Strength, $\mathrm{x}_{\mathrm{Csatu}}=$ Mixture of one, $\mathrm{x}_{\mathrm{cdua}}=$ Mixture of two, $\mathrm{x}_{\mathrm{P}}=$ Polymer

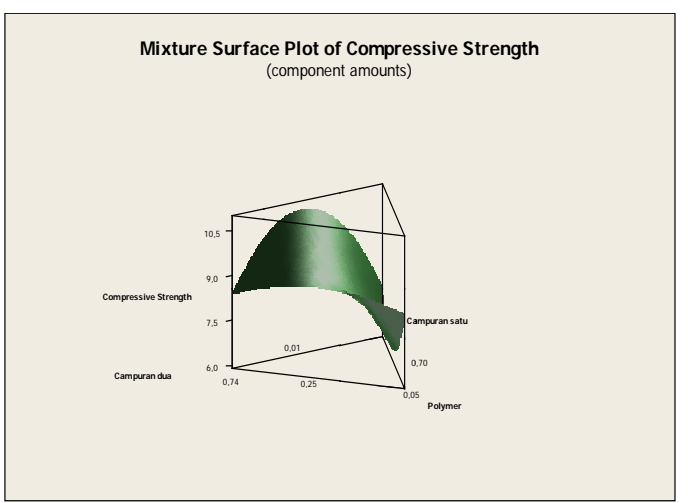

Figure 2. Surface of plot equation 8.

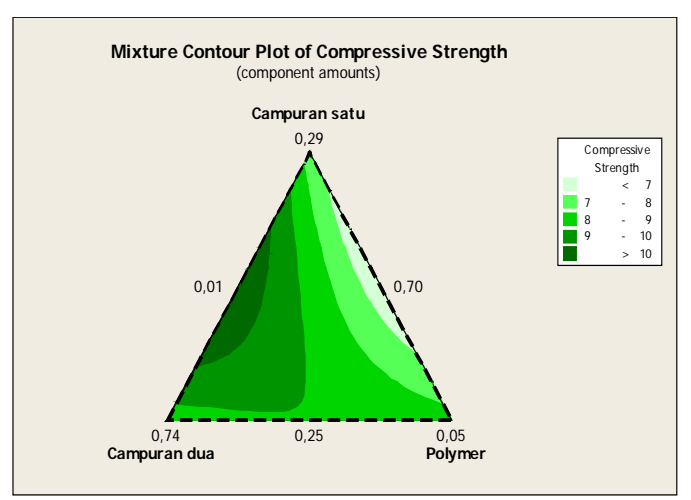

Figure 3. Countur plot. 


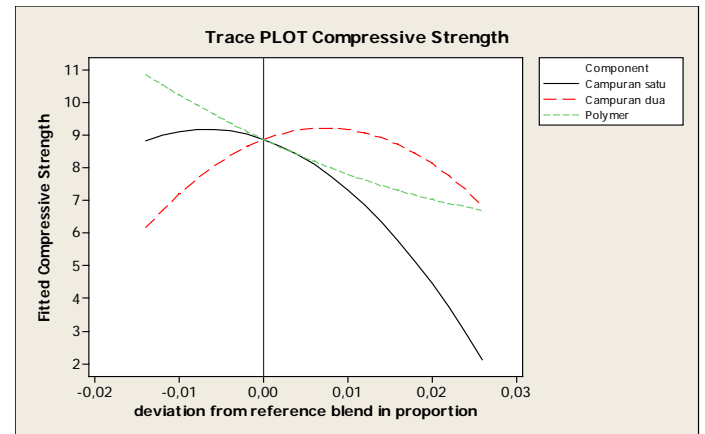

Figure 4. Trace plot of equations 8.

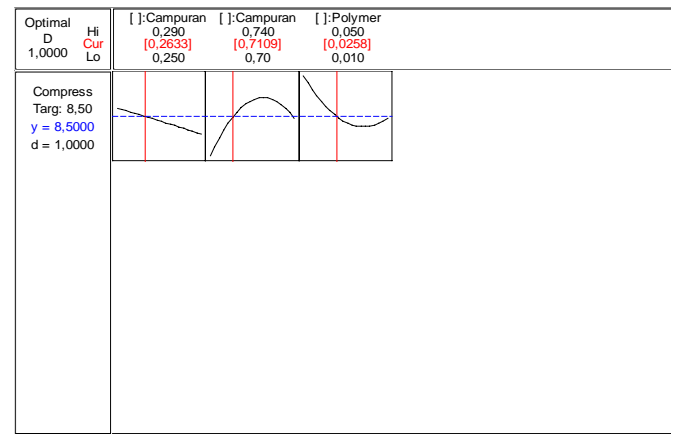

Figure 5. Optimum components.

If the mathematical model equation obtained in equation (8), depicted in cartesius coordinates of three dimensional planes, then the model can be described as a curved plane. As in Figure 2, and if the curved area is projected in the two dimensional plane then the contour plot will be obtained as shown in Figure 3. Its compressive strength $\left(\mathrm{N} / \mathrm{mm}^{2}\right)$ will be below 7 which are indicated by light green and above 10 indicated by dark green. While the effect of mixed composition on increasing or decreasing compressive strength can be seen in the trace plot (Figure: 4).

Addition of 0.01 mixture of one (black color) will result in compressive strength of 7 . The addition of 0.01 polymer (green) will result in compressive strength of 7.5 and the addition of 0.01 mixture of two (red) will result in compressive strength of 9.2. To see the optimal condition is in Figure 5, it turns out that the optimal composition of the three mixture is $26.33 \%$ mixed one, $71.03 \%$ mixture two, $2.58 \%$ polymer. Acquisition of the composite for the mixture was $83.22 \%$ Water, $10 \%$ Latex and $6.78 \%$ Pigment, while the second mixture consisted of $21.16 \%$ White Cement, $40 \% \mathrm{CaCO}_{3}$ and 38.84\% Fine Aggregate.

Thus the optimal total mixture for Skimcoat cement with $30 \mathrm{~kg}$ weight are: Water (21.91\%), Latex (2.6\%), Pigment (1.78\%), White cement (15.12\%), $\mathrm{CaCO}_{3}$ (28.41\%), Fine Aggregate (27.58\%) and Polymer (2.5\%).

\section{Conclusion}

The conclusions obtained from this research are composition of optimum skimcoat cement mixture comprised of water as large as $21.91 \%$, latex $2.6 \%$, pigment $1.78 \%$, white cement $15.12 \%$, $\mathrm{CaCO}_{3}$ $28.41 \%$, fine aggregate $27, .58 \%$ and polymer of $2.5 \%$. Compressive Srentgh will increase by 7 N/ $\mathrm{mm}^{2}$ if added 0.01 mixture of two, will increase to $7.5 \mathrm{~N} / \mathrm{mm}^{2}$ if added by 0.01 polymer and will increase by $9.2 \mathrm{~N} / \mathrm{mm}^{2}$ if added 0.01 mixture of two.

\section{References}

1. Montgomery DC. Design and analysis of experiments. Hoboken, New Jersey: John Wiley \& Sons; 2009. $656 \mathrm{p}$. 